\title{
Inhaltsübersicht
}

Vierter Abschnitt

Abänderungen des Gesellschaftsvertrages

Bearbeiter

$\$ 53$ Form der Satzungsänderung

Ulmer

$\$ 54$ Anmeldung und Eintragung

$\$ 55$ Erhöhung des Stammkapitals

$\$ 56$ Kapitalerhöhung mit Sacheinlagen

$\$ 56$ a Leistungen auf das neue Stammkapital

$\$ 57$ Anmeldung der Erhöhung

$\$ 57$ a Ablehnung der Eintragung

$\$ 57 \mathrm{~b}$ Bekanntmachung der Eintragung der Kapitalerhöhung

Anhang: Kapitalerhöhung aus Gesellschaftsmitteln

$\$ 58$ Herabsetzung des Stammkapitals

$\$ 59$ Zweigniederlassung

\section{Fünfter Abschnitt}

\section{Auflösung und Nichtigkeit der Gesellschaft}

$\$ 60$ Auflösungsgründe

Anhang: Auflösung nach dem Gesetz über die Aufhebung und Löschung von Gesellschaften und Genossenschaften

$\$ 61$ Auflösung durch Urteil

$\$ 62$ Auflösung durch Verwaltungsbehörde

$\$ 63$ Konkursverfahren

$\$ 64$ Konkursantragspflicht

$\$ 65$ Anmeldung der Auflösung

Hohner

$\$ 66$ Liquidatoren

$\$ 67$ Anmeldung der Liquidatoren

$\$ 68$ Zeichnung der Liquidatoren

$\$ 69$ Rechtsverhältnisse von Gesellschaft und Gesellschaftern

\$ 70 Aufgaben der Liquidatoren

$\$ 71$ Bilanz; Rechte und Pflichten

$\$ 72$ Vermögensverteilung

$\$ 73$ Sperrjahr

$\$ 74$ Bücher und Schriften

$\$ 75$ Nichtigkeitsklage

$\$ 76$ Mängelheilung durch Gesellschafterbeschluß

$\$ 77$ Wirkung der Nichtigkeit

Anhang I: Umwandlungsgesetz

II: Verschmelzungsgesetz

Schilling

Schilling/Zutt 


\section{Inhaltsübersicht}

Sechster Abschnitt

Bearbeiter

Schlußbestimmungen

$\$ 78$ Anmeldungspflichtige

Ulmer

$\$ 79$ Zwangsgelder

Kohlmann

$\$ 80$ (aufgehoben)

$\$ 81$ a (aufgehoben)

Vorbemerkungen vor $\$ 82$

$\$ 82$ Falsche Angaben

$\$ 83$ (aufgehoben)

\$84 Pflichtverletzung bei Verlust, Zahlungsunfähigkeit oder Überschuldung

$\$ 85$ Verletzung der Geheimhaltungspflicht 